\title{
REFLEXIONES SOBRE EL NEOLÍTICO ANDALUZ
}

\section{DISCUSSING THE ANDALUSIAN NEOLITHIC}

\author{
por
}

\author{
BEATRIZ GAVILÁN CEBALLOS
}

RESUMEN Desde hace algunos años la investigación sobre el Neolítico en Andalucía ha avanzado considerablemente, sobresaliendo la detección de bastantes hábitats al aire libre. Sin embargo, son objeto de controversia algunos aspectos importantes, como su origen y desarrollo cultural y económico. Consideramos que no están tratados con el suficiente rigor o, cuando menos, se proponen hipótesis muy a la ligera, a lo que hay que sumar que en un mismo término se incluyen conjuntos industriales, culturales y cronológicos diferentes.

\begin{abstract}
The last few years have witnessed an important development on the Andalucian Neolithic research. It is worth mentioning the location of several open-air sites. However, in the study of the Andalucian Neolithic, there are still many controversial aspects such as its origin, cultural and economic development. We believe that such aspects have not been seriously considered and that many hypothesis have been put forward. Moreover, several different lithic, cultural and chronological complexes have been included under the same term.
\end{abstract}

\section{HIPÓTESIS SOBRE LA AUTOCTONÍA DEL NEOLÍTICO ANDALUZ}

De acuerdo con la definición del Neolítico como período de la Prehistoria en el cual se pasa de una economía exclusivamente cazadora-recolectora a otra productora que conlleva el desarrollo de nuevas formas de organización social (Vicent 1988; 1990), opinamos que económicamente el Neolítico en Andalucía, y en cualquier otra región, no puede ser autóctono si previamente no se documenta la existencia de agriotipos en el territorio peninsular, siendo necesario aceptar algún mecanismo de difusión para explicar la presencia de, al menos, ovicápridos y cereales. Diferente caso plantean suidos y bóvidos, cuyos ancestros existían en la Península Ibérica, siendo factible una domesticación local. 
Aunque sobre los orígenes del Neolítico peninsular y andaluz han insistido otros autores (Fortea y Martí 1984-85) indicando con argumentos de peso que no se puede plantear un autoctonismo, nuevos trabajos de campo han desembocado en la formulación de hipótesis en su favor.

No pretendemos desarrollar la historiografía sobre el Neolítico en Andalucía, sino resumir brevemente las propuestas sobre su origen a partir de los años sesenta.

En dicha década, ante la mayor abundancia de cerámicas impresas cardiales en Levante en relación con Andalucía oriental, se concreta que este sector se neolitizó debido a la expansión del Neolítico levantino (Pellicer 1964), llegando a la costa posteriormente, puesto que la fase inicial de Nerja es paralela a la media de Carihuela, indicándose que de ser coetáneos su origen debe ser diferente.

Al respecto, Muñoz (1975) plantea la existencia de dos tradiciones culturales distintas y sincrónicas, una representada por la cerámica cardial de Carihuela y la otra por las impresas no cardiales y las almagras de la cueva de Zuheros y de las situadas en la costa malagueña, que penetraría a través del norte de África.

En los años ochenta y noventa asistimos a un radical cambio de postura en algunos autores debido a nuevas excavaciones y a la obtención de fechas absolutas.

Así, Acosta y Pellicer (1990) se manifiestan decididamente autoctonistas, proponiendo para Andalucía occidental un Neolítico no cardial, con predominio de cerámicas a la almagra, cuyo foco de origen sitúan en las sierras gaditanas a partir de las altas fechas radiocarbónicas obtenidas en las cuevas de Dehesilla, en Cádiz, y Chica de Santiago, en Sevilla, que se remontan a finales del VII milenio y comienzos del VI cal a.C. (Acosta 1995)

Consideramos que aunque se aceptasen las altas dataciones, éstas no prueban la autoctonía sino, todo lo más, un Neolítico muy antiguo. En ninguno de los trabajos publicados sobre las estratigrafías de las cuevas de Cádiz y Sevilla se menciona la existencia de industrias epipaleolíticas, pareciendo desprenderse que su primera ocupación es neolítica (Acosta 1986; Acosta y Pellicer 1990), no observándose, por tanto, una evolución interna a partir de un sustrato previo. Además, ambos autores aceptan la existencia de contactos con el exterior a la hora de explicar la presencia de cereales y ovicápridos domésticos, lo cual resulta contradictorio con el autoctonismo que defienden.

La segunda propuesta tiene como defensores al equipo encabezado por J. Ramos Muñoz, y parte, por un lado, del análisis de la industria lítica tallada (Ramos et alii 1994 a), por otro, de la presencia de semillas silvestres en contextos del Neolítico Medio y, finalmente, de determinadas manifestaciones parietales paleolíticas (Ramos et alii 1995-96).

Los autores indican que se observa una continuidad en la industria lítica tallada desde el Solutrense Superior Evolucionado al Neolítico (Ramos et alii 1994 a). Creemos que sus fundamentos al respecto son realmente débiles al tratarse principalmente de industrias de superficie, que pocas conclusiones permiten extraer para analizar con más cuidado "las bases de explicación del origen del Neolítico" (Ramos et alii 1994 a: 288 ).

Los casos de Dehesilla, con una exigua industria de tradición epipaleolítica, o de Nerja, con ese sustrato documentado y con una cantidad escasa de dicha industria en los primeros niveles neolíticos, representarían la confirmación de la citada hipótesis. Sin embargo, el valor porcentual de dichos útiles se sobrevalora en extremo. En los niveles del Neolítico Antiguo sólo hay: 2 raspadores, 3 bordes abatidos, 1 buril, en Dehesilla; 1 raspador, 1 buril y 1 hojita de dorso, en Nerja. De este modo, el peso del sustrato epipaleolítico como argumento en favor de la autoctonía del Neolítico andaluz no es tan fuerte como pretende este equipo.

Por su parte, la presencia de algunas semillas -bellotas, piñones y algarrobas, entre otras-en asentamientos como Dehesilla, Toro o Nerja reflejan, según Ramos, formas y alternativas locales de cultivo (Ramos et alii 1995-96). Creemos que habría que aclarar si se trata de especies silvestres, como verdaderamente parecen ser (Buxó 1997), o cultivadas, y explicar entonces por qué el cultivo, desde que se constata en nuestra región, se desarrolla a partir de especies foráneas y no precisamente en las autóctonas. Basar la producción en 
dichas especies, que no presentan cambios genéticos constatados arqueobotánicamente, resulta difícil de aceptar puesto que no se trataría de domesticación, sino de recolección. Consideramos que tales especies, presentes en numerosos asentamientos correspondientes a los primeros productores de alimentos, responden más que a un cultivo autóctono a una actividad económica que combina la práctica agrícola con la recolección, al igual que sucede con la cría de animales domésticos y la caza de especies salvajes.

Finalmente, asegurar la autoctonía de la domesticación animal a partir de la representación parietal paleolítica de determinadas especies -équidos, bóvidos y cápridos- (Ramos et alii 1995-96), nos parece un tanto arriesgado sobre todo en el caso de los cápridos.

Particularmente opinamos que soslayando la existencia en el Neolítico de otros conjuntos no constatados con anterioridad y, principalmente, sin agriotipos, no se puede hablar de autoctonía, sino de grupos a los que, aunque evolucionen internamente y se especialicen en la explotación de determinados recursos, les llega la economía de producción forzosamente de fuera según los datos con que contamos por el momento.

Así pues, ninguno de los argumentos que se esgrimen para defender la autoctonía del Neolítico andaluz tienen el suficiente peso y, desde luego, no queda claro qué se entiende por tal autoctonismo.

\section{EL NEOLÍTICO ANDALUZ: FASES Y CARACTERIZACIÓN}

Generalmente se acepta una división tripartita del Neolítico andaluz: Antiguo, Medio y Final o Reciente (Molina 1983; Asquerino 1987; Acosta y Pellicer 1990; Navarrete et alii 1991), duramente criticada como normativista, pero a las que sus mismos detractores se acogen sistemática y cómodamente (Ramos et alii 1995-1996) sin proponer otra. Dado que esta división se basa en las técnicas decorativas de la cerámica, nos centraremos en algunas de ellas, ofreciendo posteriormente un comentario sobre la industria lítica tallada.

La postura más tradicional (Navarrete et alii 1991) caracteriza la Fase Antigua por la cerámica cardial, abundante en la Cueva de la Carihuela y escasa en otras estratigrafías como la de Nerja (Pellicer y Acosta 1986), o la de Lebrija (Caro et alii 1986), entre otras; y la Fase Media por la abundancia de cerámica a la almagra, impresa no cardial, incisa, con decoración plástica y no decorada, principalmente. Por último, se define el Neolítico Final bien por un descenso de las cerámicas decoradas, bien por el "horizonte de las cazuelas carenadas".

La mayoría de los yacimientos neolíticos de Andalucía se adjudican a las fases Media y Final (Molina 1983; Navarrete et alii 1991). No obstante, hay que tener en cuenta: a) la existencia de un Neolítico no cardial de cronología paralela al Antiguo levantino; b) la adjudicación del "horizonte de las cazuelas carenadas" tanto al Neolítico Final como al Calcolítico Antiguo; y, finalmente, c) la caracterización de la industria lítica tallada.

\section{a) Existencia de un Neolítico Antiguo no cardial}

En Andalucía, salvo Carihuela, en la mayoría de los niveles que marcan el comienzo del Neolítico la cerámica cardial es escasa o está ausente. Sin embargo, algunos investigadores (Molina 1983; Navarrete et alii 1991) hacen concordar ese inicio con los niveles correspondientes al Neolítico Medio de Carihuela, retrasando así el de todo el periodo.

En contra de esto opinamos que la coexistencia en Carihuela de cardiales y almagras desde el estrato XV puede obedecer a que este yacimiento represente, no el exponente del Neolítico Antiguo en Andalucía, sino un cruce entre las tradiciones de las regiones andaluza y levantina. En esta última, en la Fase IA1 de Bernabeu (1989), también se documentan almagras. Por otro lado, las dataciones obtenidas recientemente 
en algunos yacimientos -caso de Murciélagos de Zuheros, con una serie coherente que abarca desde el $4.480 \pm 130$ a.C. al $4.240 \pm 120$ a. C., I-17.772 y I-17.771, sin calibrar, para el comienzo de la ocupación neolítica-muestran una correspondencia con las fechas de la Fase IA2 propuesta por Bernabeu (1989) para el Neolítico Antiguo levantino.

Al hilo de lo expuesto, interpretar este hecho como ausencia de Neolítico Antiguo en la mayor parte de Andalucía plantea el problema de la definición de la primera ocupación neolítica de Murciélagos de Zuheros, entre otros asentamientos. Según la secuencia levantina habría que considerarla como Neolítico Medio por la ausencia de impresas cardiales, pero contemporánea al Neolítico Antiguo cardial de Levante en su Fase IB 1 (Bernabeu 1989), de manera que sólo podríamos llamar Neolítico Antiguo en Andalucía a los conjuntos con escaso cardial. La presencia de esta técnica decorativa en el sur peninsular, exceptuando Carihuela, puede tener el mismo valor testimonial que la almagra en la Fase Ia1 del Neolítico levantino (Bernabeu 1989), y nos preguntamos si no habría que considerar unas y otras más como fruto de contactos entre los grupos instalados en ambas regiones que de expansiones.

Teniendo en cuenta que el binomio Neolítico Antiguo-Neolítico cardial no se cumple en la totalidad de los casos en el Levante español (Schuhmacher y Weniger 1995), antes de aceptar dicho binomio para Andalucía es necesario contar con más secuencias, ya que la mayoría de las estaciones que han proporcionado cerámica cardial apuntan hacia un Neolítico definido por el predominio de otras decoraciones, siendo de la opinión de que la presencia de algunas cerámicas cardiales no basta para adjudicar automáticamente un asentamiento al Neolítico Antiguo, sobre todo a partir de materiales de superficie.

Opinamos que las marcadas diferencias que se advierten desde el principio entre el Neolítico andaluz y el levantino indican que es necesario abandonar la hipótesis de que toda la región andaluza se neolitiza a partir del Levante español. Este puede ser el caso de ciertos sectores de Andalucía oriental, pero la neolitización de la mayor parte de la región no puede explicarse satisfactoriamente mediante dicha extensión. Así, somos partidarios de reconsiderar positivamente la hipótesis propuesta por Muñoz (1975).

\section{b) Adjudicación del "horizonte de las cazuelas carenadas" tanto al Neolítico Final como al inicio del Calcolítico}

Estas formas cerámicas representan el final del Neolítico (Arribas y Molina 1979), un Neolítico Atlántico Tardío (Escacena et alii 1996), una etapa de tránsito (Hurtado 1987) y, por último, el comienzo del Calcolítico (Martín de la Cruz 1994). Resulta interesante señalar que, en ocasiones, un mismo investigador incluye dentro del Neolítico Final tanto a los conjuntos empobrecidos que aparecen en las estratigrafías, principalmente en cuevas y algunas estaciones al aire libre (Ramos 1993), como al horizonte definido por las cazuelas carenadas (Ramos et alii 1994c). Otras veces estas formas representan el Neolítico Final en un sector (Carrilero y Martínez 1985), y en otro el Calcolítico Antiguo (Carrilero y Suárez 1989-90).

Este horizonte muestra una serie de diferencias con respecto a los conjuntos generalmente presentes en los asentamientos en cueva, aunque no con exclusividad en este tipo de asentamiento, como son una notable disminución de las técnicas decorativas en la cerámica, descenso acusado de hojas de sílex de tamaño pequeño sustituyéndose por otras de mayor longitud, aumento de los pulimentados, aparición de elementos nuevos tales como puntas de flecha y cazuelas carenadas y, en lo que al hábitat se refiere, una preferencia por las zonas llanas y abiertas y un absoluto predominio por el establecimiento al aire libre.

Estas diferencias y nuevos elementos han llevado a Escacena (Escacena et alii 1996) a proponer que se trata de una tradición neolítica distinta de procedencia foránea, norteafricana, al no detectarse en otras tradiciones neolíticas del resto de la región un cambio gradual en el que se vislumbre el desarrollo de estos tecnocomplejos. De igual modo, señala una economía más ganadera que agrícola para estos grupos. 
No estamos en condiciones de pronunciarnos ni a favor ni en contra de su propuesta de origen sobre este horizonte; pero si, como ciertamente parece, el modo de vida de estos grupos no ha cambiado sustancialmente con respecto al de los de tradición mediterránea representado en mayor medida, por el momento, en las cuevas, habrá que considerar a los grupos responsables de los primeros asentamientos de este horizonte igualmente neolíticos, aunque respondiendo a una tradición diferente, y darán lugar, transcurrido cierto tiempo y sin ruptura, a la serie de transformaciones socio-económicas que, entre otras, definen el Calcolítico.

De este modo, queda patente un desacuerdo en lo que concierne a la caracterización de las fases Antigua y Final del Neolítico en Andalucía.

\section{c) La caracterización de la industria lítica tallada neolítica}

Este conjunto industrial requiere una profunda y seria revisión. J. Ramos ha dedicado numerosos trabajos a definir sus características a partir, principalmente, de supuestos "talleres" y de materiales superficiales, indicando que existe una "buena representación del sustrato epipaleolítico, común y normal, en los conjuntos neolíticos andaluces de superficie" (Ramos 1988-89: 126) (la negrita es nuestra), ante esta afirmación no resulta extraño que, sin aportar ningún argumento, atribuya al Neolítico determinados yacimientos adjudicados al Epipaleolítico, como Los Llanos de Jarcas (Gavilán 1987). En este caso, el autor demuestra un desconocimiento de las industrias líticas -contextualizadas- de los yacimientos neolíticos de la zona en la que se ubica la citada estación. Su industria no resulta paralelizable, en su gran mayoría, con los conjuntos líticos de los niveles neolíticos documentados tanto en la Cueva de los Mármoles (Asquerino 1987) como en los de las últimas excavaciones realizadas en Murciélagos de Zuheros (Gavilán y Vera 1992), pero sí con los recuperados en niveles más antiguos de esta última cavidad.

Las características generales de cualquier conjunto industrial no pueden establecerse a partir de materiales de superficie, sino de secuencias, y las que tenemos por ahora indican que el peso del sustrato epipaleolítico no es tan fuerte como se pretende. Desde luego, salvo Nerja y, quizá, Dehesilla, los útiles que pueden mostrar la continuidad con la tradición anterior son muy escasos en sí mismos y respecto al resto de la industria lítica. De manera que, en nuestra opinión, Ramos (1988-89) sobrevalora en extremo la importancia del sustrato, sin negársela en estaciones como las de Nacimiento y Valdecuevas al tratarse de epipaleolíticos neolitizados (Fortea et alii 1988).

Por otra parte, se adjudican al Neolítico (Ramos et alii 1994 a) yacimientos que han aportado escasos conjuntos industriales: Huerta de la Compañía con 13 piezas (1 moleta, 5 núcleos, 3 lascas, 1 esquirla, 3 útiles: 1 truncatura, 1 retoque simple y 1 retoque abrupto); Casa de Soto con 17 elementos ( 1 núcleo, 4 lascas, 4 esquirlas, 7 desechos y 1 raspador); y Pago del Retamillo con 12 artefactos de similares características. Con tales restos resulta arriesgada no sólo una atribución cultural, sino la propia caracterización de las industrias, puesto que la mayoría de las piezas corresponden a restos de talla.

\section{CUESTIONES EN TORNO AL DESARROLLO ECONÓMICO DEL NEOLÍTICO ANDALUZ}

Pese al aumento de las estaciones excavadas, los datos escasean bastante, siendo difícil establecer una evolución. Empero, apuntaremos algunos comentarios con los que pretendemos dar un toque de atención referido al cultivo de cereales.

Desde el comienzo del Neolítico se constata en Andalucía la cría de ovicápridos, suidos y bóvidos, con predominio de los primeros, aunque con diferentes valores porcentuales según el yacimiento. Se indica que los datos que proporcionan las estratigrafías ponen de manifiesto que en Andalucía la cría de animales 
precede a la agricultura (Asquerino 1987; Acosta y Pellicer 1990), cuya práctica se generalizaría en la Fase Media y, sobre todo, en la Final (Pellicer y Acosta 1986; Acosta y Pellicer 1990). Es posible que esto no corresponda a la realidad en todos los casos.

Hasta el momento se cuenta con evidencias directas de cultivo desde los comienzos del Neolítico en las cuevas de Murciélagos de Zuheros (Vicent y Muñoz 1973; Gavilán y Vera 1992), Mármoles (Asquerino 1987) y Toro (Martín et alii 1985), así como en el asentamiento al aire libre de los Castillejos de Montefrío (Afonso et alii 1996), perteneciendo los restos de Nerja (Pellicer y Acosta 1986) y Carihuela a la Fase Final. Teniendo en cuenta que según los datos disponibles actualmente los cereales tienen una procedencia foránea, llama la atención que se documenten primero en el centro geográfico de Andalucía. Su ausencia en determinados asentamientos y su presencia a partir del Neolítico Final -en estructuras de almacenamiento como es el caso concreto de Nerja-, puede obedecer, más que a la verdadera ausencia de cultivo, a que posiblemente el sedimento no ha sido procesado adecuadamente. Mediante la criba de agua se ha detectado cereal cultivado en las recientes excavaciones en las cuevas del Toro (Málaga), Mármoles, Mina y Murciélagos de Zuheros (Córdoba), entre otras, y en Castillejos de Montefrío (Granada).

No queremos indicar que la agricultura tuviera la misma importancia económica en todos estos yacimientos, ni que fuese una base económica fuerte, sino sólo poner de manifiesto que cuando se aplica una metodología adecuada a la hora de procesar el sedimento, los cereales cultivados suelen documentarse, aunque sea en pequeñas cantidades. Debe tenerse en cuenta que no siempre se logra encontrar un almacenamiento de cereal, del tipo que sea, en el transcurso de una excavación.

De manera que no somos partidarios de aceptar que en Andalucía la cría de animales domésticos precediera a la agricultura, siendo factible que esta última práctica económica fuese más frecuente y generalizada de lo que se piensa. Hasta que no se aúnen las metodologías de recuperación de restos vegetales quedaremos estancados en la situación actual, en la que es imposible determinar el peso de la economía agrícola frente a la ganadera.

\section{PLANTEAMIENTOS Y REFLEXIONES EN TORNO A LA ECONOMÍA DESARROLLADA DURANTE EL NEOLÍTICO EN LOS DIFERENTES TIPOS DE ECOSISTEMAS}

Quizá la supuesta ausencia de agricultura en la mayoría de los yacimientos neolíticos en cueva excavados hasta el momento, unida a la localización de un elevado número de estaciones en la campiña, entre otros aspectos, ha llevado a determinados autores (Molina 1983; Ramos et alii 1994 a,b; Gutiérrez et alii 1996) a afirmar que el Neolítico de la sierra es retardatario con respecto al de la campiña, estableciendo un binomio entre un Neolítico en cueva con economía ganadera y cazadora-recolectora y un Neolítico al aire libre con economía agrícola.

Sin excluir que en los terrenos de campiña se llevara a cabo una economía agrícola y ganadera, la riqueza de los suelos que rodean a los hábitats no es razón suficiente para conceder mayor importancia a la agricultura respecto a la ganadería. Tampoco basta para admitir que en los conjuntos serranos se practicara sólo, o principalmente, una economía cazadora-recolectora y, a lo sumo, una agricultura marginal, puesto que bastantes de las cavidades con ocupación neolítica están rodeadas de terrenos de valor agrícola.

Para apoyar la primacía de la relevancia de la economía pastoril sobre la agrícola en los sectores serranos se acude también al porcentaje de animales domésticos-60\% en Murciélagos de Zuheros, $75 \%$ en Castillejos de Montefrío-(Molina 1983; Carrilero y Martínez 1985). Sin embargo, como ya hemos indicado, los escasos datos referidos a las prácticas agrícolas no permiten desvelar cuál fue el peso relativo de ganadería y agricultura.

La caza, la pesca y la recolección no son únicamente actividades "continuadoras de modos de vida epipaleolíticos" (Ramos 1988-89: 117), perduran hasta momentos muy avanzados de la Prehistoria, y opinamos 
que responden al aprovechamiento lógico de unos recursos al alcance. Si como afirma Ramos (1988-89), los grupos neolíticos que ocupan las cuevas practican una economía retardataria muy adaptada a los anteriores modos de vida, con caza y recolección, cabría preguntarse si, por el contrario, los grupos instalados al aire libre, en espacios abiertos y, por lo tanto, en "medios más dinámicos", desestimaron los recursos correspondientes. La debilidad de esa argumentación queda clara cuando también se propone una actividad cazadora-recolectora con escasa domesticación para interpretar los hallazgos superficiales en medios análogos de San Fernando (Ramos et alii 1994b), y habría que considerar a estos grupos igualmente retardatarios, puesto que no practican una "economía desarrollada".

Los estudios sobre economía sobrevaloran en sus interpretaciones la importancia del medio (Ramos 1988-89: 118) abandonando una adecuada metodología de recuperación de restos vegetales. Al hacerlo se refuerza el presupuesto de que en la sierra la actividad económica por excelencia es la ganadera y en la campiña la agrícola. Esta extrapolación de la actualidad a la Prehistoria conlleva riesgos y obvia, además, que bastantes conjuntos serranos se han explotado hasta no hace muchos años, y con buenos rendimientos.

Por otra parte, el citado autor (Ibídem) considera que el supuesto retardatarismo de los grupos serranos viene avalado también por las industrias líticas, a las que sin análisis traceológicos previos adjudica funciones concretas, indicando que los útiles relacionados con la caza -geométricos- tienen lógicamente mayor representación en los conjuntos serranos, sobre todo en el Subbético cordobés, mientras que están ausentes o escasamente representados los relacionados con las prácticas agrícolas, como los elementos de hoz. Hemos de decir que contamos con bastantes de estas últimas piezas en el Subbético cordobés y que tras ser sometidas a un análisis de pulido y huellas de uso se ha podido determinar su empleo para la siega de cereales (Ibáñez y González 1996), (Vera e.p.). De este modo, y atendiendo ahora a este conjunto industrial, el carácter retardatario de estas poblaciones carece de sentido.

Opinamos que ni las dataciones -dejando de lado las altas fechas obtenidas en algunas cuevas andaluzas-, ni los restos materiales, ni las amplias secuencias -que muestran una ocupación prolongada y bastante permanente en determinadas cavidades frente a la gran mayoría de los asentamientos situados al aire libre, de corta ocupación-ni, lo que es más importante, la economía productora, con cría de animales y agricultura -constatada en los escasos asentamientos en los que se ha flotado el sedimento-, permiten conceder un carácter retardatario al "Neolítico serrano", cazador-ganadero, frente a otro mucho más dinámico en la campiña, con economía principalmente agrícola.

La "pátina de siega" en determinados útiles y hojas, las piezas activas y pasivas de molino, entre otros elementos, presentes también en los conjuntos serranos, avalan para algunos investigadores una producción agrícola (Ramos et alii 1994a,b). Sin embargo, la "pátina de siega" puede deberse a vegetales no cultivados y en los molinos pueden molturarse gran cantidad de productos silvestres y materias inorgánicas. Es necesario contar con evidencias más directas a la hora de asegurar la práctica de una agricultura, sobre todo por parte de las primeras comunidades productoras, y no sólo acudir al valor agrícola de las tierras de la campiña, puesto que la disponibilidad de un recurso no implica, forzosamente, su explotación.

Consideramos que existe un Neolítico homogéneo tanto en los terrenos de campiña como en los conjuntos serranos, pero con diferencias ergológicas según las zonas y sectores. Dichas diferencias deben estar en función, entre otros factores no menos importantes, de los recursos susceptibles de explotación existentes en el entorno. No nos parece aceptable, en cambio, con los escasos datos disponibles, admitir una economía ganadera y cazadora-recolectora, y a lo sumo una agricultura "marginal" o "residual" (Molina 1983; Navarrete et alii 1991), para todos los yacimientos situados en sierra, y otra agrícola más desarrollada para los ubicados en zonas de campiña. Es precisamente en los primeros donde, por el momento, se han documentado las evidencias directas de cultivo, contando algunos de ellos con llanos de alto valor agrícola situados a corta distancia del asentamiento, ya sea cueva, abrigo o al aire libre. 
Sí nos parece lógico el establecimiento de grupos en determinados enclaves especializados. Así, algunas de las estaciones dadas a conocer por J. Ramos (Ramos et alii 1994a,b) en San Fernando deben responder al aprovechamiento periódico de unos recursos - costeros, caza, recolección-por parte de un grupo que podría ser el mismo dada la escasa distancia las separa, en vez de a unos modos de vida cuya base principal descansa sobre la caza y la recolección. Asimismo, determinadas cuevas del Subbético cordobés están situadas en terrenos sólo aptos para la caza, recolección y ganadería (Gavilán 1991).

Abundando sobre el carácter supuestamente retardatario del Neolítico serrano frente al de la campiña, se afirma que las prácticas económicas de los grupos serranos al estar escasamente desarrolladas "no conllevan importantes cambios económicos, no desencadenan excedentes, capaces de alterar dinámicas sociales; con lo que estas comunidades tienden a ser conservadoras y retardatarias, en sus formaciones económicas, políticas y sociológicas" (Ramos 1988-89: 119). Este planteamiento lleva implícita, por un lado, la negación de contacto, por otro, la presunción de que cada grupo sólo ocupa un determinado medio, cuando, como muy bien indican Schuhmacher y Weniger (1995), la ocupación y explotación de diferentes zonas por parte de un mismo grupo parece más probable y acorde con el patrón de asentamiento de estas primeras sociedades productoras.

Igualmente, Carrilero y Martínez (1985) sostienen que los yacimientos al aire libre detectados en la Campiña cordobesa, cercanos a Murciélagos de Zuheros, se desarrollaron con total independencia de los instalados en el Subbético. La proximidad de los yacimientos situados en ambos medios y la semejanza entre sus conjuntos industriales, unida a la presencia de determinados fósiles como desgrasantes en algunas de las cerámicas de Murciélagos de Zuheros, que proceden, entre otros lugares, de la campiña de Castro del Río (Barrios et alii e.p.), nos llevan a desestimar esa desconexión.

A una conexión e intercambio entre distintos grupos apuntan la presencia de brazaletes de mármol y concha, o el uso del cinabrio como colorante en zonas donde no existen dichas materias primas (Barrios et alii e.p.), y los caracoles marinos empleados como colgantes que se documentan en yacimientos bastante alejados de la costa.

\section{PLANTEAMIENTOS SOBRE LA SUPUESTA SALIDA DE LAS CUEVAS A PARTIR DEL NEOLÍTICO FINAL}

Finalmente, hemos de manifestar nuestro desacuerdo con la hipótesis, aún vigente, que sostiene que las primeras sociedades productoras ocuparon primero las cuevas, estableciéndose al aire libre a partir de la Fase Media (Navarrete et alii 1991).

Las estaciones al aire libre se documentan desde el comienzo del Neolítico y a lo largo de todo el período, como se desprende del elevado número de asentamientos detectados. Citamos sólo algunas a modo de ejemplo: Esperilla, en Cádiz (Gutiérrez et alii 1996); Lebrija (Caro et alii 1990), Las Barrancas y Los Álamos (Fernández y Gavilán 1995), en Sevilla; Guta, San Joaquín, La Polonia (Carrilero y Martínez 1985), Cerro del Cercado, Cerro de la Taberna (Gavilán y Vera 1996), en Córdoba; Castillejos de Montefrío (Arribas y Molina 1979), La Molaina (Sáez y Martínez 1981), en Granada. Así pues, la investigación ha estado mediatizada por dos factores. En primer lugar, los yacimientos situados en cueva y/o abrigos rocosos son más fácilmente detectables que los situados en espacios abiertos, expuestos a fuertes fenómenos de erosión de distinta índole. En segundo lugar, se ha supuesto un carácter troglodita a los últimos cazadores-recolectores, que se perpetuaría a lo largo del período siguiente. Sin embargo, y según los datos publicados sobre la mayoría de las estratigrafías en cueva de nuestra región, el Epipaleolítico suele estar ausente, debiéndose encontrar, por tanto, en mayor medida al aire libre. 
En conclusión, consideramos que las propuestas sobre la autoctonía del Neolítico en Andalucía no pueden mantenerse si no se constatan los agriotipos tanto de cereales como de ovicápridos, de manera que, particularmente, admitimos un mecanismo de difusión para explicar el comienzo de la economía productora en nuestra región. Por otra parte, creemos necesario descartar la idea, arraigada profundamente en algunos investigadores, de seguir proponiendo una adscripción cultural a partir de la presencia y/o ausencia de determinadas especies cerámicas. En cuanto a las industrias líticas talladas, hemos de decir que el peso del sustrato no es tan fuerte como se pretende si tenemos presente que las estadísticas se han realizado a partir de escasísimas piezas. Sobre el supuesto carácter retardatario de los grupos instalados en medios serranos, creemos haber puesto de manifiesto que los datos económicos y los análisis traceológicos desmienten tal retardatarismo, debiéndose tener en cuenta, además, que estos primeros productores de alimentos todavía no son totalmente sedentarios, poniendo en explotación distintos medios y ecosistemas y, desde luego, manteniendo una serie de contactos a diferentes niveles como indican la presencia de determinadas materias primas en zonas alejadas de su procedencia.

\section{BIBLIOGRAFÍA}

ACOSTA, P. (1986): “El Neolítico en Andalucía Occidental. Estado actual”. Homenaje a L. Siret (1934-1984). Sevilla: 136-151.

(1995): "Las Culturas del Neolítico y Calcolítico en Andalucía Occidental." Espacio, Tiempo y Forma, Serie I, Prehistoria y Arqueología, 8: 33-80.

ACOSTA, P. y PELLICER, M. (1990): La Cueva de la Dehesilla (Jerez de la Frontera). Las primeras civilizaciones productoras en Andalucía Occidental. Jerez de la Frontera.

AFONSO, J.A.; MOLINA, F.; CÁMARA, J.A.; MORENO, M.; RAMOS, U. y RODRÍGUEZ, Mª O. (1996): "Espacio y tiempo. La secuencia en los Castillejos de las Peñas de los Gitanos (Montefrío, Granada)". I Congrés del Neolític a la Península lbèrica. (Gavá 1995) Vol. 1.: 297-304. Rubricatum, Museu de Gavá. ARRIBAS, A. y MOLINA, F. (1979): El poblado de <Los Castillejos> en las Peñas de los Gitanos (Montefrío, Granada). Campaña de excavaciones de 1971. El Corte n ${ }^{\circ}$. 1. C.P.U.Gr., Serie Monográfica no 3.

ASQUERINO, M. D. (1987): "El Neolítico en Andalucía: Estado actual de su conocimiento". T.P., 44: 63-85.

BARRIOS, J.; GAVILÁN, B.; MARTÍNEZ, M.J. y MONTEALEGRE, L. (e.p.): “Caracterización de cerámicas neolíticas procedentes de la Cueva de los Murciélagos, Córdoba". Segunda Reunión de Arqueometría. I Congreso Nacional. (Granada 1995).

BERNABEU, J. (1989): La tradición cultura de las cerámicas impresas en la zona oriental de la Península Ibérica. S.I.P., Serie de Trabajos Varios, nº 86. Diputación Provincial de Valencia.

BUXÓ, R. (1997): Arqueología de las Plantas. La explotación económica de las semillas y los frutos en el marco mediterráneo de la Península lbérica. Crítica, Barcelona.

CARO, A.; ACOSTA, P. y ESCACENA, J.L. (1990): "Informe sobre la prospección arqueológica con sondeo estratigráfico en el solar de la calle Alcazaba (Lebrija, Sevilla)". A.A. A. II Actividades Sistemáticas. 168-174. Sevilla.

CARRILERO, M. y MARTíNEZ, G. (1985): "El yacimiento de Guta (Castro del Río, Córdoba) y la Prehistoria Reciente de la Campiña cordobesa". C.P.U.Gr., nº. 10: 187-223.

CARRILERO, M. y SUÁREZ, A. (1989-90): "Ciavieja (El Ejido, Almería): Resultados obtenidos en las campañas de 1985 y 1986. El poblado de la Edad del Cobre". C.P.U.Gr., 14-15: 109-136. 
ESCACENA, J.L.; RODRÍGUEZ DE ZULOAGA, M. y LADRÓNDEGUEVARA, I. (1996): Guadalquivir Salobre. Elaboración prehistórica de sal marina en las antiguas Bocas del Río. Confederación Hidrográfica del Guadalquivir, Sevilla.

FERNÁNDEZ, J.J. y GAVILÁN, B. (1995): "Yacimientos neolíticos en el río Corbones (Sevilla)". Spal, 4: 25-67.

FORTEA, F.J. y MARTÍ, B. (1984-85): “Consideraciones sobre los inicios del Neolítico en el Mediterráneo español”. Zephyrus, XXXVII-XXXVIII: 167-199.

FORTEA, F.J.; MARTI, B. y CABANILLES, J. (1988): "L'industrie lithique du Néolithique Ancien dans le versant méditerranéen de la peninsule iberique". Archaeologia Interregionalis. Chipped stone industries of the early farming cultures in Europe. Warsaw University. Jagiellonian University Cracow: 521-542.

GAVILÁN, B. (1987): "El yacimiento Epipaleolítico de los Llanos de Jarcas (Cabra, Córdoba)". Estudios de Prehistoria Cordobesa, 2: 7-27.

- (1991): “Análisis macroespacial de ocho yacimientos neolíticos en cueva de la Subbética cordobesa: Una contribución al estudio de la explotación de recursos durante la Prehistoria". Cu.P.A.U.A.M., 18:35-53.

GAVILÁN, B. y VERA, J.C. (1992): "Breve avance sobre los resultados obtenidos en la excavación arqueológica de urgencia en la Cueva de los Murciélagos de Zuheros (Córdoba)". Antiqvitas, 3: 23-30. Museo Histórico de Priego de Córdoba.

(1996): "Estaciones neolíticas al aire libre en el Sureste de la provincia de Córdoba". Antiqvitas, 7-18. Museo Histórico de Priego de Córdoba.

GUTIÉRREZ, J.M.; PRIETO, M.C. y RUIZ, J.A. (1996): “Yacimientos neolíticos al aire libre con cardiales: El asentamiento al aire libre de Esperilla (Espera, Cádiz). Propuesta de otro modelo de neolitización para Andalucía Occidental". I Congrés del Neolitic a la Península Ibèrica. (Gavá 1995), Vol. II: 627-638. Rubricatum, Museu de Gavá.

HURTADO, V. (1987): "El megalitismo en el Suroeste peninsular: problemática en la periodización regional". El Megalitismo en la Península Ibérica. 31-43. Madrid.

MARTÍN, D.; CAMALICH, M. D. y GONZÁLEZ, P. (1985): “Informe preliminar de la campaña de 1985 en la Cueva de El Toro de El Torcal (Antequera, Málaga)". A.A.A. II. Actividades Sistemáticas: 233-240.

MARTÍN DE LA CRUZ, J.C. (1994): Los poblados del Neolítico-Cobre Inicial en el litoral del Suroeste peninsular. E.A.E., 169. Madrid.

MOLINA, F. (1983): Historia de Granada. I. De las primeras culturas al Islam. Primera parte. Prehistoria. 7-131. Ed. Don Quijote.

MUÑOZ, A.M. (1975): “Consideraciones sobre el Neolítico español”. Memoria del Instituto de Arqueología y Prehistoria. Universidad de Barcelona: 27-40.

NAVARRETE, M.S.; CAPEL, J.; LINARES, J.; HUERTAS, F. y REYES, E. (1991): Cerámicas neolíticas de la provincia de Granada. Materias primas y técnicas de manufacturación. Colección Monográfica Arte y Arqueología, $n^{\circ}$. 9. Univ. de Granada.

PELLICER, M. (1964): "La cerámica impresa del Neolítico Inicial en el Mediterráneo Occidental". Zephyrus, XV: 101-124.

PELLICER, M y ACOSTA, P. (1986): “Neolítico y Calcolítico de la Cueva de Nerja”. En J. Jordá Pardo (coord): La Prehistoria de la Cueva de Nerja (Málaga). Trabajos sobre la Cueva de Nerja, $n^{\circ}$. 1:341-450. Málaga.

RAMOS, J. (1988-89): "La industrias líticas del Neolítico en Andalucía, sus implicaciones espaciales y económicas". Zephyrus, XLI-XLII: 113-148.

— (1993): El hábitat prehistórico de <El Estanquillo> (San Fernando, Cádiz). San Fernando, Cádiz. 
RAMOS, J.; SÁEZ, A.; CASTAÑEDA, V.; PÉREZ, M. y CEPILLO, J.J. (1994 a): "La ocupación neolítica". en J. Ramos, A. Sáez, V. Castañeda y M. Pérez (coord): Aproximación a la Prehistoria de San Fernando. Un modelo de poblamiento periférico en la Banda Atlántica de Cádiz. San Fernando: 255-296. Cádiz.

RAMOS, J.; SÁEZ, A.; CASTAÑEDA, V. y CEPILLO, J.J. (1994 b): “Aproximación al poblamiento neolítico de San Fernando (Cádiz). Inferencias socio-económicas y enmarque en el contexto regional". Antiqvitas, 5: 13-21. Museo Histórico de Priego de Córdoba.

RAMOS, J.; CASTAÑEDA, V.; PÉREZ, M. y LAZARICH, M. (1994 c): "Las ocupaciones humanas de la Prehistoria Reciente de la campiña litoral y banda atlántica de Cádiz". Gibraltar during the Quaternary, 71-90. AEQUA Monografías, 2.

RAMOS, J.; CASTAÑEDA, V.; PÉREZ, M.; LAZARICH, M. y MONTAÑÉS, M. (1995-1996): “Aportaciones al estudio del modo de producción de los cazadores-recolectores especializados y al inicio de la economía de producción en la Banda Atlántica de Cádiz (Sur de España)". Boletín del Museo de Cádiz, VII: 7-35. Cádiz.

SÁEZ, L. y MARTÍNEZ, G. (1981): "El yacimiento neolítico al aire libre de la Molaina (Pinos Puente, Granada)". C.P.U.Gr., n ${ }^{\circ}$. 6: 17-34.

SCHUHMACHER, Th. X. y WENIGER, G.C. (1995): "Continuidad y cambio. Problemas de la neolitización en el Este de la Península Ibérica". T.P., 52, no. 2, pp.: 83-97.

VERA, J.C. (e.p.): “Algunos aspectos tecno-tipológicos y morfo-funcionales de industrias líticas del Neolítico andaluz". C.N.A. (Cartagena 1997).

VICENT, A.M. y MUÑOZ, A.M.(1973): Segunda campaña de excavaciones en la Cueva de los Murciélagos, Zuheros (Córdoba) 1969. E.A.E., 77. Madrid.

VICENT, J.M. (1988): "El origen de la economía productora. Breve introducción a la Historia de las Ideas". En P. López (coord.): El Neolítico en España. Ed. Cátedra, Madrid: 11-58.

VICENT, J.M. (1990): "El neolitic: transformacions socials i economiques". En J. Anfruns y E. Llobet (eds): El canvi cultural a la Prehistória. pp.: 241-294. Barcelona. 